\title{
A Different Perspective of Pakistan's Economy: The Structure of Expenditures and Prices, 1975-81
}

\author{
ALAN HESTON ${ }^{*}$
}

This paper presents comparisons of the purchasing power of the Pakistani rupee in 1975 with those of the currency units of 33 other countries in the same year, based on the UN International Comparison Project and examines relative price structure in Pakistan compared to those in other countries. Pakistan's price level and structure are similar to those of many developing countries, although the prices of investment goods were unusually high. The paper also updates the results to 1982 and finds that the decline in the purchasing power of the rupee is fairly consistent with relative inflation rates.

It has been customary to analyse the structure and performance of the economy of Pakistan from the production side because this is the simplest way to generate national income statistics, and a natural focus for planning investments and setting many kinds of policies. This paper offers another perspective of the structure of Pakistan's economy and its growth during the 1975-1981 period. The material presented here is not a substitute for more usual analyses of industrial and agricultural growth, but rather offers complementary information, and an international comparison of Pakistan from a different perspective. Finally, this paper will introduce the reader to some of the results of the third phase of the UN International Comparison Project (ICP).

The ICP attempts to compare real product across countries by converting national expenditure aggregates to a common currency by means of purchasing power parities (PPPs). The PPPs are in turn estimated through detailed price comparisons across countries, and through combining of the individual item price ratios into purchasing power parities for the 150 expenditure categories into which the ICP divides the GDP. The aggregation of the category PPPs and expenditures of different countries presents familiar index number problems; the ICP has not solved these, but the methods employed are base country invariant, and allow each country's expenditures to be expressed in a common currency that can be added down the column of expenditures for each country, and directly compared in quantitative 
terms across countries. These methods and procedures are discussed in great detail in the recently published report of Phase III. [2], referred to below as the Phase III report.

The original motivation for the ICP, which was established on the recommendation of the Statistical Commission of the United Nations in 1968, was to provide a more satisfactory basis than exchange rates for converting GDP and other national aggregates across countries. The disadvantage of the exchange rate, even when it is freely fluctuating, is that it is based on international transactions of traded goods (almost one-half of GDP consists of non-tradables), and in addition is influenced by capital movements. Recent experience with fluctuating exchange rates suggests another problem with their use in international comparisons; certainly no one believes that the 20-percent devaluation of the rupee in Pakistan in 1982 meant that its GDP had fallen relative to the GDPs of those countries whose exchange rates were unchanged. As will also become clear below, it is usually inappropriate to use one conversion factor for different components of GDP, because price structures differ markedly across countries. For example, in 1975 an office visit to a doctor cost Rs. 19 , while the U.S. price was about $\$ 18.00$ or a price ratio of about Rs.1.05/\$. In 1975 per capita health expenditures were $\$ 653.70$ in the U.S. and Rs. 71.95 in Pakistan; an exchange rate conversion would imply that the quantity of medical services per capita was only 1.1 percent of that in the U.S. ((71.95/9.931)/653.70). Even the rough price ratio for an office visit is likely to yield a more meaningful conversion, putting Pakistan at about 10.4 percent of the U.S. ((71.95/1.05)/653.70).

Phase I of the ICP included 10 countries for 1967 and 1970 and was published in 1975; Phase II published in 1978 included 16 countries for 1970 and 1973, and Phase III in which Pakistan participated for the first time includes 34 countries for 1975. Phase IV, with 1980 as a reference, will involve about 70 countries.

Table 1 summarizes the results of Phase III for all 34 countries. Following the discussion of Table 1 in Part A, Part B provides a detailed analysis of the price structure of Pakistan with respect to all 34 Phase III countries, as well as a select group of reference countries. In Part C, the results for Pakistan for 1975 will be updated to 1981 , and the results will be compared with alternative measures of recent growth in Pakistan.

\section{A. THE BASIC RESULTS}

In Table 1, the 34 ICP countries are arrayed in order of increasing real GDP per capita in 1975. As given in Column (9), the per capita real GDP of Pakistan is 8.22 percent of that of the U.S., which is the numeraire country. This result is obtained by converting the 1975 national GDP of 1879 rupees per capita at the PPP over GDP of $3.18 \mathrm{PR}$, to obtain an international dollar total of $590^{1}$, and dividing it by the

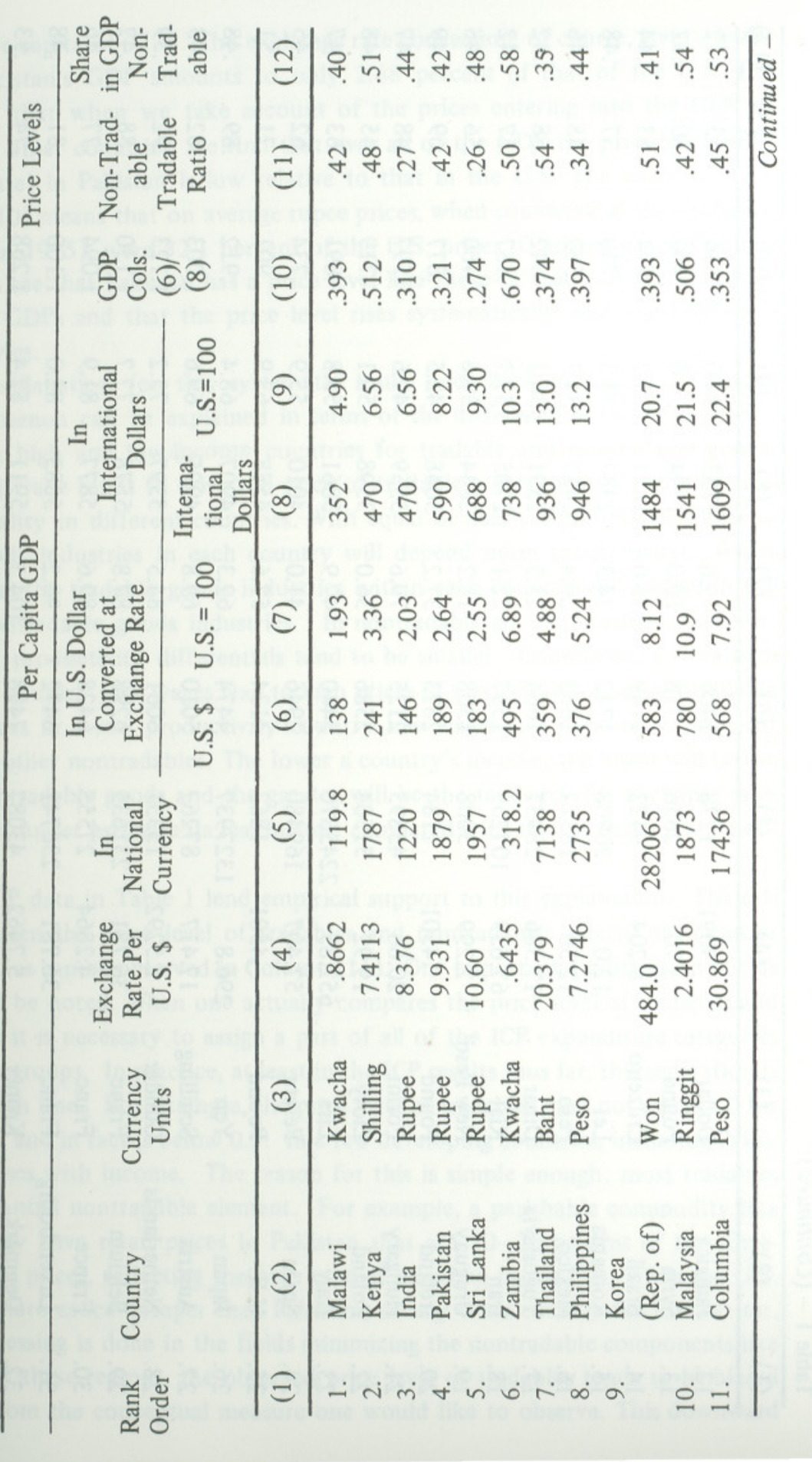

${ }^{1}$ An international dollar has the same purchasing power as a U.S. dollar in 1975 overall of GDP but not of the components. 
U.S. GDP per capita of 7176 . The exchange rate conversion, of course, gives a lower number: Pakistan's GDP amounts to only 2.68 percent of that of the U.S. The difference is that when we take account of the prices entering into the GDP of Pakistan and other countries, we find that over all of the GDP the price level (PPP/ Exchange Rate) in Pakistan is low relative to that in the U.S. The entry of 32.1 in Column (10) means that on average rupee prices, when converted at the exchange rate (9.931 in 1975), were 32.1 percent of the U.S. prices. Glancing down Column (10), we can see that Pakistan has a price level like those of many of the countries with similar GDPs and that the price level rises systematically with the GDP level across countries.

One explanation for this systematic result goes back at least to Ricardo. "The phenomenon can be explained in terms of the difference in the productivity gap between high and low-income countries for tradable and nontradable goods. International trade tends to drive the price of tradable goods, mainly commodities, towards equality in different countries. With equal or nearly equal prices, wages in tradable goods industries in each country will depend upon productivity. Wages established in the tradable goods industries within each country will prevail in the country's nontradable goods industries. In nontradable goods industries, however, international productivity differentials tend to be smaller. Consequently, in a high productivity country high wages lead to high prices of services and other nontradable goods, whereas in a low productivity country low wages give rise to low prices of services and other nontradables. The lower a country's income, the lower will be the prices of nontradable goods and the greater will be the tendency for exchange-rateconversion to under estimate its real income compared with that of richer countries" $[1]$.

The ICP data in Table 1 lend empirical support to this explanation. The difference between the price level of tradables and nontradables clearly decreases as income rises, as can be observed in Column (11). One important qualification of this result should be noted. When one actually compares the price level of tradables and nontradables it is necessary to assign a part of all of the ICP expenditure categories to these two groups. In practice, at least in the ICP results thus far, this separation is at best a rough one. For example, the price level of tradables does not equal 1.0 for all countries, and in fact is below 0.5 . In a few developing countries, including Pakistan, but it rises with income. The reason for this is simple enough: most tradables have a substantial nontradable element. For example, a perishable commodity like tomatoes, may have retail prices in Pakistan that are 10-20 percent of the corresponding U.S. prices, reflecting the high cost of handling in the U.S., while the U.S. produces tomato sauce cheaper than Pakistan, or any other country for that matter, because processing is done in the fields minimizing the nontradable components like handling. For these reasons, the observed price level of tradables tends to be biased downward from the conceptual measure one would like to observe. This downward 
bias is larger for developing countries, because of their lower prices of nontradables. As a consequence, the ratio of the price level of nontradables to that of tradables would be smaller for the lower income countries, and would rise more rapidly than is the case in Column (11).

Further, measured nontradable prices have a component of tradables that tends to overstate them, probably more so far developing countries. For example, migration of carpenters to the Gulf countries for employment tends to drive up the price of construction a "nontradable", in Pakistan. Thus if correctly measured the numerator in Column (11) would be smaller and the denominator larger in low income countries, so that the true ratio would rise more sharply than the actual results in Table 1. We may conclude this introductory section by noting that comparisons of price levels across countries indicate that they systematically rise with level of income, as the price level of nontradables is relatively lower in low income countries because of productivity differences being less between the two sectors, tradables and non-tradables, than in industrial countries. Finally, it is quite consistent for a country to have a low price level over all of GDP, and still have an "overvalued" exchange rate.

\section{B. THE PRICE STRUCTURE OF PAKISTAN}

The ICP compares prices of products purchased by the final user, so that taxes and subsidies are included. Put another way, a comparison of prices across countries does not necessarily tell us about domestic resource cost of different items. The prices being compared across countries have elements of comparative advantage and elements of pricing policy by governments mixed together in different proportions. We have yet to find a motorcycle costing more than a car in any country, and in fact, quite the other way around; usually we have found the price structure of quite different types of economies, like Romania or Hungary, and Japan or the U.S. to be surprisingly similar.

There are two principal ways of comparing price structures, one of which is to compare price levels of different components of the GDP. This is illustrated in Columns (3) and (4) of Table 2, where the price levels of Pakistan and of Group-1 ICP countries (the first 8 countries in Table 1) are given for various components of the GDP. It is possible to compare the Pakistan price level of food (Row 2) of 43.2 percent with the 49.8 percent for the reference group of countries, or a more expensive category like transport equipment (Row 25), where the values are 199.4 percent and 159 percent. The one drawback of these comparisons is that they do depend on the exchange rate ruling at the moment. An alternative measure that is independent of the exchange rate, is preferred by the ICP, and is illustrated in Columns (5) and (6).

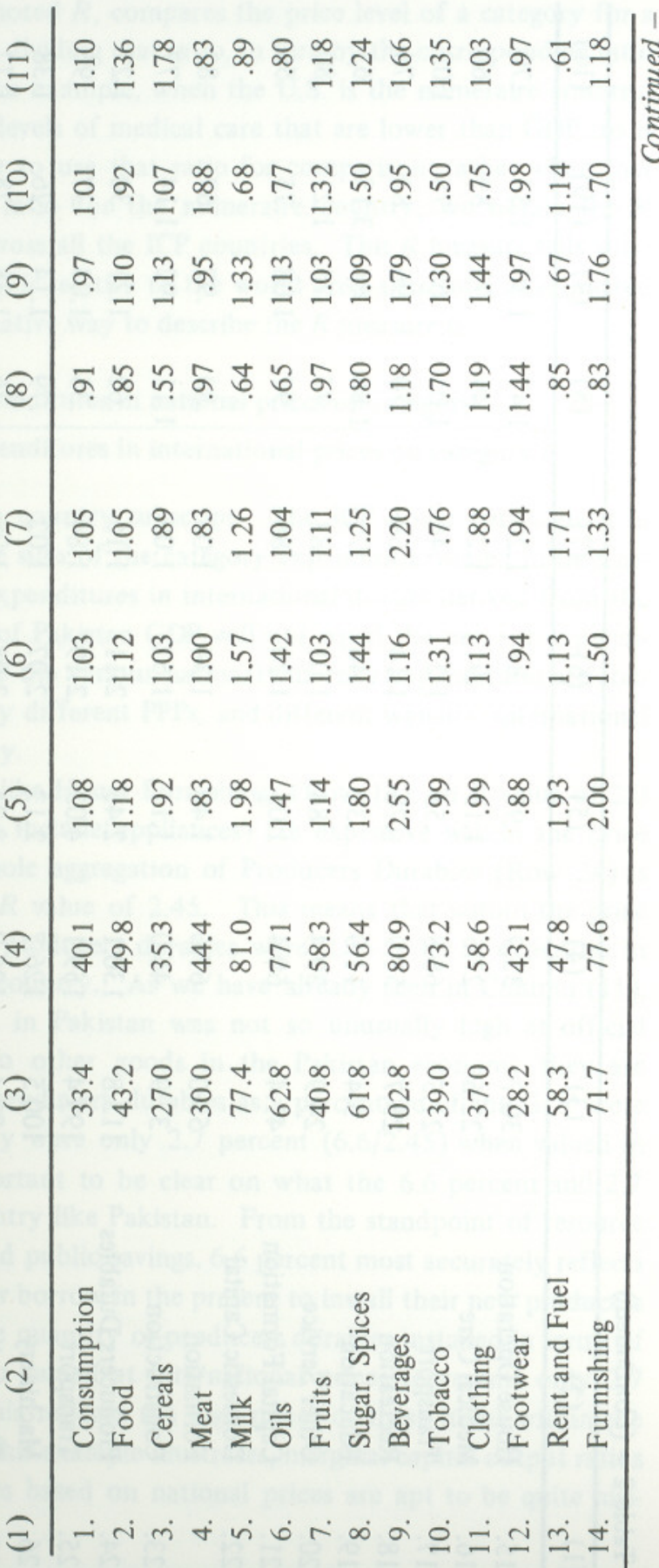




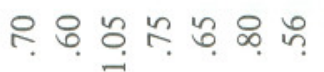

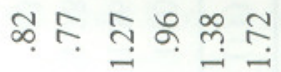

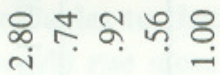

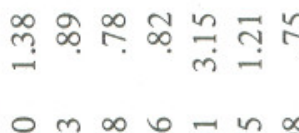

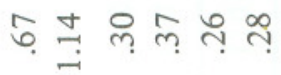

ల్లి 웅요

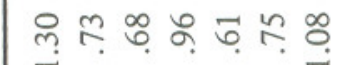

ธิธ సิ ํㅜㄹ

守

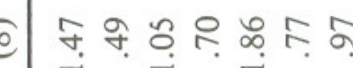

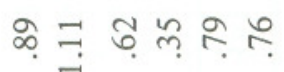

పุ? 年

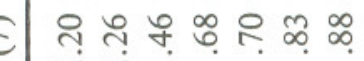

ڤุ.

œ

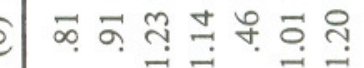

m.

구

â.

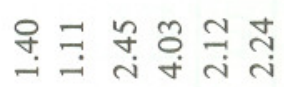

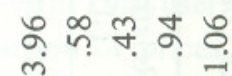

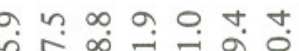

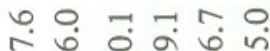

$\rightarrow+\sin$

ले त远

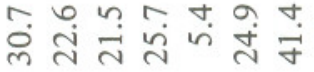

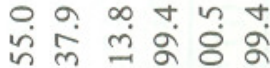

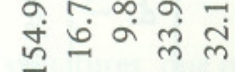

This second measure denoted $R$, compares the price level of a category for a country to its GDP price level, dividing that ratio, in turn by the corresponding ratio for the numeraire country. For example, when the U.S. is the numeraire country, most countries will have price levels of medical care that are lower than GDP, so it would not be very informative to use that ratio for comparison; rather when that ratio is divided by the same ratio for the numeraire country, we obtain the $R$ measure, which averages 1.0 across all the ICP countries. This $R$ measure tells what the price structure of a country is relative to the world price structure, as estimated from the ICP sample. An alternative way to describe the $R$ measure is:

$$
R_{i j}=\frac{\text { Percentage of expenditures in national prices on category } i}{\text { Percentage of expenditures in international prices on category } i}
$$

where $i$ is a category, and $j$ a country subscript. The ICP dollar totals given in Column (8) of Table 1 are the sum of the category expenditure valued in international dollars; the percentage expenditures in international dollars derived from the various expenditure categories of Pakistan GDP will not equal the percent expenditures in national currency, since the various national currency expenditures are converted to numeraire currency by different PPPs, and different weights (international prices) are used for each category.

If we look at a category like House Furnishings (Row 14), an $R$ value of 2.0 means that these items (which include appliances) are expensive within the price structure of Pakistan. The whole aggregation of Producers Durables (Row 24) is even more expensive, with an $R$ value of 2.45 . This means that within the price structure of Pakistan in 1975, producers durables were 2.45 times as expensive in Pakistan as in an average ICP country. As we have already seen in Column (11), the price level of these goods in Pakistan was not so unusually high at official exchange rates, but relative to other goods in the Pakistan economy they are expensive. In national prices producers durables as a percentage of the GDP were 6.6 percent in 1975 , while they were only 2.7 percent $(6.6 / 2.45)$ when valued in international prices. It is important to be clear on what the 6.6 percent and 2.7 percent figures mean for a country like Pakistan. From the standpoint of resource mobilization through private and public savings, 6.6 percent most accurately reflects what Pakistan had to set aside or borrow in the present to install their new producers durables in 1975. However, the quantity of producers durables installed in terms of their capacity to produce when valued at international prices represents only 2.7 percent of Pakistan's GDP. This reflects the high prices of these items within the price structure of Pakistan. As this example illustrates, marginal capital output ratios when compared across countries based on national prices are apt to be quite misleading. 
As is illustrated in Columns (5) and (6), Pakistan shares with many other developing countries, relatively high prices of producers durables, and relatively low prices of education and other government services. ${ }^{2}$ Another way of looking at Pakistan's internal price structure is to express it relative to the reference group of countries. This is given in Column (7). Where Column (7) numbers differ greatly from 1.0, the interpretation is that relative to a group of countries with similar incomes the price structure in Pakistan is unusually low (for example, transportation and communication in Row 17), or relatively expensive (other producers durables, which include instruments - (Row 28)). In Columns (8) to (11) are given two Group-1 countries from the region (India and Sri Lanka), a centrally planned economy (Hungary) and a relatively affluent Asian country (Japan). The figures for these countries are comparable to those in Column (7), which are the $R$ values for each category for the economy divided by the $R$ value for the Group -1 countries.

In general there are more similarities in price structure by level of income than by type of economic system, so Hungary and Japan tend to share more similar values with each other than with the three South Asian countries. ${ }^{3}$ However, the South Asian countries, while generally similar, show some noticeable differences, due partly to measurement problems (the rent estimates (Row (13)) are probably too high for Pakistan), and others to different policies, e.g., the very high prices of transport equipment in Pakistan. While they cannot be fully explored here, there are some generalizations that can be made from these country comparisons.

First, we have already noted that investment goods tend to be relatively expensive in developing countries, despite the fact that construction is relatively cheap. In general the $R$ values for capital formation decline with income, and as can be seen in Row 22, Japan, despite having relatively higher construction costs, tends to have relative prices of capital formation that are two-thirds of the Group-1 countries. The relatively high prices of capital formation in developing countries have obvious implications for cross section growth studies, and planning models.

Secondly, the generalization that service shares rise with income, which originated with Colin Clark, as partly a proposition about production, though it was extended to expenditures, appears to need revision. When the service categories are

${ }^{2}$ It should be noted that in the ICP all health and education expenditures whether financed from the public or private purse, are treated as part of consumption. Also, the comparisons for health and education are mainly based on indirect PPPs derived from direct quantity comparisons of per capita teachers, students, doctors, hospital bed days, and similar measures. The comparisons of government compensation are based on categories of trained personnel, with a rough adjustment for capital per worker.

This statement finds some support in Table 2 , but is more systematically examined in Chapter 9 of the Phase III Report. There, similarity indexes of prices and quantities have been computed for all possible pairs of the 34 ICP countries. For the price comparisons the similarity index is the raw correlation between the $R$ values for the 150 detailed categories of expenditure. In Table 9.1 of that Report, the similarity indexes for Pakistan for prices are .936 with India, .899 with Sri Lanka, and .843 with U.S. For all countries, the similarity indexes of price tend to be largest for countries with similar income compared with commodity categories, as in Table 2, we find that this proposition does not hold. For example the share of services in Pakistan in the 1975 national prices was 20.9 percent while in international prices it was 32.0 percent whereas for the U.S. the corresponding figures are 43.9 percent and 32.3 percent. This pattern holds for all the Phase-III countries, namely, that the share of services in total GDP when valued at common prices does not tend to rise with income. Essentially, the income elasticity of demand for services may be greater than 1.0, but the steep rise in relative prices of services with income leads to an offsetting decline in their real quantities consumed in the more affluent countries.

\section{UPDATING THE RESULTS}

The method used to update the PPPs for Pakistan from 1975 to later dates has been based on the relative price movements between the numeraire country, the U.S., and Pakistan. Column (3) of Table 3 gives the expenditure weight in the 1975 international dollars for Pakistan for various aggregations of detailed expenditure categories. Column (4) provides the 1975 PPPs in Rs./\$, where the U.S. is 1.0 for each category. ${ }^{4}$ In Column (5) these have been updated to January 1982 on the basis of the item or group price comparisons between Pakistan and the U.S. Column (6) indicates the number of price comparisons underlying the extrapolation, and the extrapolation has been judged $\mathrm{A}, \mathrm{B}$, or $\mathrm{C}$, to indicate an adequate, fair, or poor basis for the extrapolation.

To illustrate further the method, if we look at cereals in Row 1, there were 7 items for which price changes in Pakistan were calculated. Weights were available for rice, wheat products, and other cereals, to estimate an overall price change for Pakistan, which was then compared with the cereals index for the U.S. ${ }^{5}$ For cereals the price index change with $1975=100$ was 183.5 in January 1982, while for the U.S. the comparable index was 148.6 . So relatively prices for cereals rose $23.59(183.5 /$ $148.6-1.0$ ). The purchasing power parity of 3.31 in Row 1 is 23.59 above its value of 2.68 Rs. $/ \$$ in 1975 . There were 7 items that could be used in this category - a number which I judged to be representative enough to give an adequate comparison.

${ }^{4}$ A technical point should be noted about the PPPs in Table 3. In Phase III, the PPPs are expressed relative to the U.S., which takes account of the fact that the PPP for the U.S. or any numeraire country for a category is not necessarily 1.0 ; it is only 1.0 over all of GDP. The consequence of this method of presentation is that the weighted average of the PPPs in Columns (2) or (3) for food, capital formation, or other aggregates, will not equal the PPP given in Table 3 for that aggregate. (Only an average, which takes account of the U.S. PPP for each category, appropriate method of extrapolating the PPP fould produce the correct average). This is why the change in Pakisthod of extrapolating the PPP for an aggregate is to weight the average price 1975 PPP.

In some of the aggregations in Table 3, U.S. price changes could be compared at more
detailed levels. In these instances the change in Prices in Pakistan relative to those in the U.S. were weighted by Pakistan weights to obtain the average relative price change for the aggregation. 
In several other categories, the price representation was much weaker, particularly for health, education, capital formation and government.

Table 3 (Preliminary)

Purchasing Power Parities of Pakistan by Summary Expenditure Categories Rs./\$, 1975 and 1982

\begin{tabular}{|c|c|c|c|c|c|}
\hline $\begin{array}{l}\text { S. } \\
\text { No. }\end{array}$ & $\begin{array}{c}\text { Expenditure } \\
\text { Category }\end{array}$ & $\begin{array}{l}\text { Expenditures } \\
1975\end{array}$ & $\begin{array}{l}\text { PPP } \\
1975\end{array}$ & $\begin{array}{c}\text { PPPs } \\
1981-82\end{array}$ & $\begin{array}{c}\text { Basis of } \\
\text { Extrapolation }\end{array}$ \\
\hline (1) & (2) & (3) & (4) & (5) & (6) \\
\hline 1. & Bread, Cereals & 99.5 & 2.68 & 3.31 & {$[7-\mathrm{A}]$} \\
\hline 2. & Meat and Fish & 25.4 & 2.98 & 3.42 & {$[5-\mathrm{A}]$} \\
\hline 3. & Milk, Butter, Eggs & 46.8 & 7.69 & 7.65 & {$[4-\mathrm{A}]$} \\
\hline 4. & Oils, Fats & 9.8 & 6.24 & 5.86 & {$[1-\mathrm{B}]$} \\
\hline 5. & Fruits and Vegetables & 28.0 & 4.05 & 5.44 & {$[9-\mathrm{A}]$} \\
\hline 6. & Coffee, Tea & 8.1 & 4.60 & 4.37 & {$[1-\mathrm{A}]$} \\
\hline 7. & Spices, Sugar & 12.2 & 6.14 & 9.37 & {$[2-B]$} \\
\hline 8. & Beverages & .2 & 10.21 & 9.72 & {$[1-\mathrm{B}]$} \\
\hline 9. & Tobacco & 11.8 & 3.87 & 5.27 & {$[1-\mathrm{A}]$} \\
\hline 10. & Clothing & 42.5 & 3.67 & 5.19 & {$[9-B]$} \\
\hline 11. & Footwear & 10.8 & 2.81 & 3.37 & {$[2-B]$} \\
\hline 12. & Rent, Maintenance & 18.7 & 4.89 & 5.99 & {$[4-\mathrm{A}]$} \\
\hline 13. & Fuels and Power & 9.9 & 8.84 & 8.32 & {$[3-B]$} \\
\hline 14. & Furniture & .9 & 7.12 & 8.82 & {$[2-B]$} \\
\hline 15. & Supplies, Household & 18.7 & 3.05 & 3.30 & {$[9-\mathrm{A}]$} \\
\hline 16. & Medical Care & 19.7 & 2.24 & 3.04 & {$[1-\mathrm{C}]$} \\
\hline 17. & Transport and Communication & n 16.8 & 2.14 & 2.60 & {$[8-\mathrm{A}]$} \\
\hline 18. & Recreation and Education & 48.1 & 1.19 & 1.28 & {$[5-\mathrm{C}]$} \\
\hline 19. & Other Consumption & 13.8 & 2.47 & 3.82 & {$[7-B]$} \\
\hline \multicolumn{6}{|c|}{ Domestic } \\
\hline 20. & Construction & 56.9 & 3.76 & 4.41 & {$[1-\mathrm{C}]$} \\
\hline 21. & Producers Durables & 15.8 & 11.30 & 10.74 & {$[3-\mathrm{C}]$} \\
\hline 22. & Government & 94.0 & 1.66 & 1.85 & {$[4-\mathrm{C}]$} \\
\hline
\end{tabular}

Source: Columns (3) and (4) from Tables 6.5 and 6.3 of the Phase III Report. Columns (5) and (6) have been discussed in the text.
The resulting PPPs for these aggregations in Column (5) were in turn used to value the quantities in Pakistan in 1981-82. The method involves using the international prices in 1975 to value the 1981-82 quantities in Pakistan. These results are given in Table 4 below. $^{6}$ In several categories, the PPPs declined, as for example for oils and fats (Row 4, Table 3), for fuels and power (Row 13) and for producers durables (Row 21). Since the results of Table 2 suggested that Pakistan prices for producers durables were quite high, this latter appears an appropriate adjustment. However, the PPP for domestic capital formation still rose by over 15 percent because of the relative rise in construction costs which, in international dollars, were almost 80 percent of capital formation in 1975. Again, the reader should note that the capital formation numbers in Table 3, are " $\mathrm{C}$ "-rated estimates as far as the relative price movements within and for the total of capital formation are concerned, and one should be appropriately generous in assigning margins of error to these results. $^{7}$

Table 4

\section{Estimates of Main Aggregates for Pakistan in 1975} International Dollars, for 1975 and 1981-82

\begin{tabular}{lrr}
\hline Per capita income measure & 1975 & $1981-82$ \\
\hline Consumption Private & 415.2 & 513.6 \\
Domestic Capital Formation & 68.4 & 74.7 \\
Government & 88.4 & 102.6 \\
Gross Domestic Product & 553.8 & 644.6 \\
Domestic Absorption & 572.0 & 690.9 \\
Domestic Absorption in Pakistan & & \\
as percent of Domestic Absorption in the U.S. & 8.0 & 8.4 \\
\hline
\end{tabular}

${ }^{6}$ This method values Pakistan output in 1981-82 at the price level of the dollar of the U.S. in 1975. The method may be illustrated for clothing. From Table 3, the estimated PPP fo clothing in 1981-82 is Rs. 5.19 per dollar. The estimated per capita rupee expenditures were Rs. 282 , or $\$ 48.80$ in 1975 international dollars comparable to Column (3). The $\$ 48.80$ is obtained by getting the nominal $1981-82$ quantity $(\$ 54=282 / 5.19)$ multiplied by the 1975 international price of 1.16 , and by the $1975 / 1981-82$ price ratio for clothing for the U.S. (.78). Another way to make the same estimate is to use the real growth rate for clothing expenditures for Pakistan and apply it to the 1975 international growth rate for clothing expenditures This latter method apply it to the 1975 international dollar amounts in Column (3) of Table 3. present method in present method in the sense that Column (5) of Table 3 involves division by the U.S. price deflator, and the above calculations in this footnote, multiplication by the same factor. We have used the round about procedure because it relied on the same items in both periods, it focused on price structure, and the growth rates were not readily available at a disaggregated level.

The underlying price indexes for the U.S. producers durables and construction are based on fairly detailed surveys. For Pakistan we have used the wholesale price indexes for transport equipment, machinery and other electrical goods for comparisons for producers durables. For construction the geometric mean of the price changes for sand, cement, bricks and iron reinforcing rods were taken to represent materials and weighted $2 / 3$, and the geometric mean of wage changes for masons, carpenters and unskilled labour were weighted $1 / 3$. Construction cos studies suggest wages to be about 20 percent of costs and overheads about 15 percent or more.
See [3]. 
In examining Table 4, it should be noted that the 1975 national accounts data used by the ICP for Pakistan were subsequently revised downward. The figures given in Table 4 thus correspond to the revision and not to Table 1.

The results in Table 4 provide an implicit growth rate for per capita GDP in Pakistan that can be compared with the growth rate from national data. There is no reason why the two series should be the same; they both depend on the price structure for 1975, but the ICP weights will be different from Pakistan weights.

For this comparison we have also used domestic absorption, as well as GDP, as the use of the former avoids the problem of deflating the trade balance, particularly the remittances. For Pakistan, the growth rate of per capita domestic absorption is 18.1 percent from the National Accounts estimates and 20.8 percent from Table 4. That is, the ICP weights and price comparisons would appear to imply a slightly higher growth rate than would be implied by the national data for domestic absorption. The situation is reversed for GDP where national growth rate for the five years is 22.9 percent, and the Table 4 estimate is 16.4 percent. This difference is much larger and its cause if not clear. However, the two sets of estimates are within the margins of error that one could attach to these estimates.

There is not much that one can infer from either Table 3 or Table 4 about the exchange rate changes that have taken place in 1982. The Table 4 numbers appearing in imply a PPP for Pakistan over domestic absorption of 3.91 in 1981-82, an increase of 15.7 percent over 3.38 Rs. $\$ \$$ for domestic absorption in 1975 . That is, these figures suggest that if 1975 represented some appropriate relation of the PPP and the exchange rate, then the devaluation of the rupee in 1982 consistent with the PPP changes would have been closer to 16 percent than to the actual 25 percent. There are several "howevers" that the reader should keep in mind. First and foremost, there is no theory that supports a rigid relation between the PPP over domestic absorption and the exchange rate, though the relation between the ratio of these variables and per capita income is very strong, as can be inferred from Table 1. Secondly, we do not know if for Pakistan, the ICP results for 1975 represent the appropriate price level that is a PPP and exchange rate that are in balance. ${ }^{8}$ Finally, the errors attached to our extrapolations must involve an error of 20 percent or more which it is hoped will lead the reader to use these results with caution.

${ }^{8}$ The structural relation described in Ch. 8 of the Phase III Report takes the nominal GDP (Column 7 of Table 1) as a function of the real GDP (Column 9 of Table 1), and a measure of openness of the economy, and other variables. In the simple relation based on the 34 Phase-III countries where $R^{2}=.970$, the estimated nominal income for Pakistan is 3.15 percent of the corresponding U.S. income versus the 2.64 percent for the actual income. Put another way, the cquation would have more accurately predicted Pakistan's value of the Rs./S exchange rate had exe African countries, Kenya and Malawi, have prediction errors in the opposite directions, for African countries, Kenya and Malawi, have prediction errors in the opp
reasons obviously not captured in the simple regression equations described.

\section{CONCLUSION}

The analysis of the price structure of the Pakistan economy presented in this paper suggests that Pakistan is fairly typical of developing countries in that the average price level was about $30-35$ percent of the numeraire country, the U.S. in both 1975 and 1981-82. These results are based on the purchasing power parity estimates of the U.N. International Comparison Project, and an extrapolations therefrom. Also, in terms of price structure, of the 34 countries examined, Pakistan is most similar to India when comparisons are based on price or quantity similarity indexes. The most striking feature of Pakistan relative to similar economies is the very high price of producers durables. A consequence of this is that the quantity of investment goods put in place in Pakistan each year tends to be overstated relative to the corresponding quantities in similar countries. However, there has been a tendency towards some reduction in the relative price of producers durables since 1975 .

\section{REFERENCES}

1. Kravis, I.B., A. Heston, and R. Summers. "New Insights into the Structure of the World Economy”. Review of Income \& Wealth. December 1981.

2. Kravis, I.B., A. Heston, and R. Summers. World Product and Income: International Comparisons of Real Gross Product. Baltimore: The Johns Hopkins University Press. 1982.

3. Nasiruddin and Associates Ltd. A Study of Structure and Capacity of the Construction Industry in Pakistan. Karachi. December 1975. (Report prepared for the Planning Commission, Government of Pakistan) 